\title{
Model Risk Management Lifecycle
}

\author{
Yousef Padganeh \\ CBI Bank, Iran
}

\begin{abstract}
Model risk refers to risk arise from using weakly developed models. The uses of models significantly increased in the financial industry globally post-financial crisis, Basel III and IFRS9 implementation. The global trend is showing that reliance to model and the risk of using models increased. Today, banks used models to meet the regulatory requirements and even their internal needs such as pricing or estimating a simple cash flow. Risk models help the bankers to make a better decision accepting some residual risks in line with the organization risk appetite. This paper aims to describe model risk management lifecycle with particular focus to the banking industry and explains the different approaches taken by industry practitioners in model risk development.
\end{abstract}

Keywords: Bank, Approach, Development, Regulators, Risk Appetite 